Research Article

\title{
Construction and Engineering Application of Salt-Discharging Model for Local Saline-Alkali Soil with Compact Structure in the Yellow River Delta
}

\author{
Chuanxiao Liu (D), Kesheng Li (D), and Depeng Ma \\ College of Water Conservancy and Civil Engineering, Shandong Agricultural University, Tai'an 271018, China \\ Correspondence should be addressed to Chuanxiao Liu; lchuanx@163.com
}

Received 25 December 2019; Accepted 29 February 2020; Published 31 March 2020

Academic Editor: Keith Smettem

Copyright (C) 2020 Chuanxiao Liu et al. This is an open access article distributed under the Creative Commons Attribution License, which permits unrestricted use, distribution, and reproduction in any medium, provided the original work is properly cited.

\begin{abstract}
Structural characteristics of local saline-alkali soil in the Yellow River Delta were studied by microscopic test methods of liquid nitrogen vacuum freeze-drying machine, fully automatic mercury intrusion porosimetry, X-ray diffractometer, and high- and low-vacuum scanning electron microscope. Permeability of the saline-alkali soil belongs to two grades of micropermeable water and extremely micropermeable water. Average volume ratio of pores with diameters no more than $2 \mu \mathrm{m}$ is $86.25 \%$; therefore, the saline-alkali soil may mainly consist of micropores and ultramicropores. Most void ratios of the soil are not beyond 0.5 , and its dry densities are all greater than $1.6 \mathrm{~g} / \mathrm{cm}^{3}$. Because average proportion of the clay minerals is only $12.24 \%$, they are obviously not the main reason for poor permeability of the local saline-alkali soil. Based on the structural characteristics of compact structure and slightly developed fracture, mechanisms of surface runoff, and water-salt migration of the local saline-alkali soil, a salt-discharging engineering model mainly with surface runoff was established considering auxiliary infiltration and without interflow. Salt content distribution of the local saline-alkali soil is studied experimentally, by which relationship between salt content and conductivity has been fitted as $y=2.74 x$. The relationships between depth and salt content in the saline-alkali soil region present that the depth of salt-discharging engineering as open ditch should be beyond $60 \mathrm{~cm}$. From the relationships between precipitation and salt content, the effectiveness of engineering measure shown in the salt-discharging model has been verified immediately or indirectly, and the engineering salt-discharging model may be suitable for managing saline-alkali soil in the Yellow River Delta.
\end{abstract}

\section{Introduction}

Agricultural development in the world has been seriously limited by the saline-alkali soils. In China, area with salinealkali degrees are increasing every year, especially in the Yellow River Delta region, where irrigation farming is mainly dependent on water from the Yellow River; severe saline-alkali soil may be due to these reasons, including lower and even land, poor drainage, side infiltration of the Yellow River water, and ascending seawater or its infiltration. The key measures to manage saline-alkali soil are to exclude soluble salt in soil and stop salt from rising. At present, combined measures involving physical, hydraulic, chemical, and biological methods are commonly recommended [1-3].
Engineering measure is a direct and effective method to control saline-alkali soil, but engineering effectiveness is easy to be lost, the material cost is high, and the economic benefit is low. To manage saline-alkali soil fundamentally, microstructure of the soil should be studied for revealing its engineering features and physical characteristics. The microstructure of soil is a determined factor and its engineering characteristics have been verified by many researchers $[4,5]$. Analyzing microstructures from consolidation test results of clay soils by X-ray diffractometer and scanning electron microscope, their deformation features of expansion, compressibility, and permeability are studied by different minerals and microstructures when ameliorating the soil with limes [6]. Microstructures and minerals of soft clay soil were identified by scanning electron microscope and X-ray 
diffractometer; meanwhile, its axial compressive strength was examined [7]. Relationships between microstructure and physical or mechanical parameters of clay soil, in Zhanjiang city, were studied by scanning electron microscope, mercury intrusion porosimetry, and gas adsorption test [8]. The results provide an important reference for the study of the relationship between the microstructure of soil and its physical and mechanical properties. These references are mainly about clay soil, soft soil, and loess, while the research on the microstructure of saline-alkali soil is less.

\section{Basic Situation of Saline-Alkali Land in the Yellow River Delta}

2.1. Natural Conditions. The Yellow River Delta is located at $118^{\circ} 07^{\prime}-119^{\circ} 10^{\prime} \mathrm{E}$ and $37^{\circ} 14^{\prime}-38^{\circ} 12^{\prime} \mathrm{N}$, and the topographic feature is level because its elevation is only between $+1.0 \mathrm{~m}$ and $+13.3 \mathrm{~m}$. Annual average precipitation in the area is about $530-630 \mathrm{~mm}$, while evaporation can be up to 750-2400 mm. The extreme temperature of the Yellow River Delta is $-23.3^{\circ} \mathrm{C}$ in winter; hence, the maximum depth of frozen soil in the Yellow River Delta is no more than $60 \mathrm{~cm}$. The depth of groundwater in the Yellow River Delta is only 0-3 $\mathrm{m}$, which is determined to form saline-alkali land [9]. Natural moisture content of the saline-alkali soil is about $22 \%$.

2.2. Influencing Factors of the Saline-Alkali Land. Formation of saline-alkali land in the Yellow River Delta has been influenced by many factors including sediment deposition, climate, salt return from seawater, and rise of groundwater level.

The sediment from the Yellow River contained a lot of salt and alkali components and buried amount of seawater, which would make the soil become saline-alkali land. The Yellow River Delta belongs to warm temperate continental monsoon climate; therefore, the groundwater and the soil water evaporate quickly. Meanwhile, soluble salts in the soil and groundwater accumulate continuously on the soil surface with evaporation of water. Development of the saline-alkali land has been affected by the return of salt from seawater by trench reverse irrigation to the groundwater and sea tide invasion to the soil. The salt and alkali gradually deposited in the soil had eventually formed unique salinealkali land in the Yellow River Delta. Rise of the groundwater level by irrigation of the Yellow River and other factors led to evaporation of the groundwater and accumulation of salt on the surface of the soil $[6,7,10]$.

2.3. Spatial and Temporal Distribution Characteristics of the Salt Content in the Saline-Alkali Land. From 1987 to 2007, the area of severe saline-alkali land in the Yellow River Delta increased rapidly. However, the area of light saline-alkali land increased and the area of heavy saline-alkali land decreased significantly from 2007 to 2014, which indicated that the degree of soil salinization was greatly related to the treatment and time [11-13].
In traditional opinion, the salinization degree of coastal saline-alkali land will be severe with the increase in depth because deeper soil may be eroded by seawater, in which conclusion should be conditional. Within $45 \mathrm{~cm}$ depth of the saline-alkali land in the Yellow River Delta, the average values of salt content are $0.68 \%(0-15 \mathrm{~cm}$ depth), $0.72 \%$ (15-30 cm depth), and $0.77 \%$ (30-45 cm depth), respectively $[14,15]$. At the depth of $0-20 \mathrm{~cm}$ below the surface of the soil in the Yellow River Delta, salt contents of the saline-alkali soil tend to be higher with the closer distance from the sea, which has been considered a general rule $[16,17]$.

2.4. Initial Effect of Research on Soil Structures to Salt-Discharging Engineering. Particle sizes of the sediments in the Yellow River will become smaller with her flowing into the sea through the estuary. In upper reaches of the Yellow River, sediments were mainly coarse-grained with a particle size greater than $0.05 \mathrm{~mm}$, loose structure, and good permeability. In her middle reaches, sediments were mainly medium coarse-grained with a particle size less than $0.05 \mathrm{~mm}$ and some developed pores. In her lower reaches, sediments were mainly fine sand with a diameter less than $0.025 \mathrm{~mm}$, a compact structure, undeveloped pores, and poor permeability, while at the estuary of the Yellow River, sediments were mainly very fine with a particle size of 0.004-0.032 $\mathrm{mm}$, very compact structure, and poor permeability [18-23].

According to structural characteristics of saline-alkali soil in the Yellow River Delta, the particle structure which was fine, uniform, and compact should be broken to improve the permeability of the soil, which was determined to harness saline-alkali soil with engineering measures. Microstructures of the local saline-alkali soil involving water permeability, porosity, dry density, mineral composition, and compact structure were studied by several microscopic test methods in this project. Considering microstructure characteristics of the local saline-alkali soil, its surface runoff mechanism, and water-salt migration mechanism, the saltdischarging engineering model is established, in which the surface runoff is determined, infiltration is auxiliary, and interflow is not included. Relationships between salt content and depth or precipitation are analyzed to evaluate the effectiveness of the salt-discharging engineering model and submit the depth of the open pitch.

\section{Structure Characteristics of the Local Saline- Alkali Soil}

In the Yellow River Delta, experimental samples of the local saline-alkali soil lie in Alfalfa grassland adjoining Shangdong Meiao Biological Engineering Co. Ltd (Guangrao County, Dongying City, Shandong Province, China; $37^{\circ} 18^{\prime} 8^{\prime \prime} \mathrm{N}$, $118^{\circ} 38^{\prime} 7^{\prime \prime} \mathrm{E}$ ), as presented in Figure 1; sampling depths are from surface to $100 \mathrm{~cm}$, the macroscopical performance of the soil samples collected is almost no stratification and compact structure, and the capillary phenomenon of groundwater may not be obvious. 

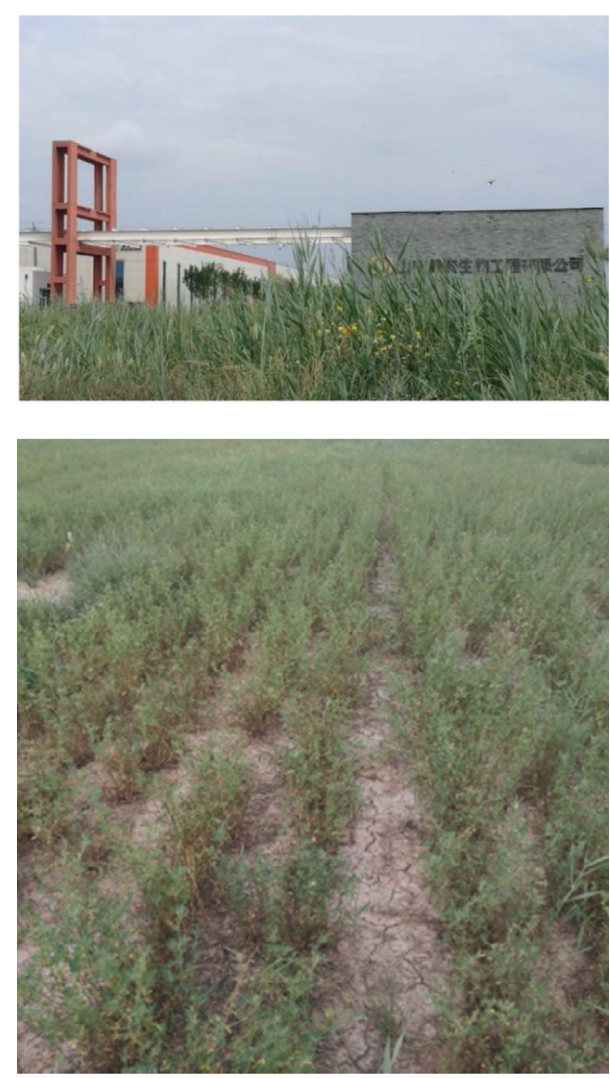

FIgURE 1: The local saline-alkali soil.

3.1. Permeability of the Local Saline-Alkali Soil. Permeability coefficients of surface saline-alkali soil at $30 \mathrm{~cm}$ depth and $60 \mathrm{~cm}$ depth are $7.14 \times 10^{-5} \mathrm{~cm} / \mathrm{s}, 3.06 \times 10^{-6} \mathrm{~cm} / \mathrm{s}$, and $8.33 \times 10^{-7} \mathrm{~cm} / \mathrm{s}$, respectively. Surface soil has looser structures and well permeability because of farming. The average permeability coefficient of the saline-alkali soil without surface soil is only $1.95 \times 10^{-6} \mathrm{~cm} / \mathrm{s}$, in which water permeability belongs to micropermeable water or extremely micropermeable water in accordance with code for engineering geological investigation of water resources and hydropower [24].

3.2. Porosity of the Local Saline-Alkali Soil. To analyze porosity of the local saline-alkali soil, soil specimens are prepared by LGJ-12N liquid nitrogen vacuum freeze-drying machine for mercury intrusion test using PM-33-18 fully automatic mercury intrusion porosimetry made in the US.

3.2.1. Volume Ratios of Pores. The volume ratio of pores is the ratio of stage cumulative mercury intrusion and complete cumulative mercury intrusion from test, and volume ratios of pores of soil samples in the surface layer and depth of $10,20,30,40,50$, and $60 \mathrm{~cm}$ of regional saline-alkali soil are shown in Table 1.

Average volume ratio of pores whose diameters are all no more than $2 \mu \mathrm{m}$ is $86.25 \%$ and that of surface soil is lower, which states that pores of the local saline-alkali soil are mainly constructed with micropores and ultramicropores.
That is to say, intergranular pores and intragranular pores are the main bodies [25]; therefore, the permeability could be extremely weak.

3.2.2. Void Ratio. By using mercury intrusion porosimetry, void ratios of the local saline-alkali soil at depths of $0,10,20$, $30,40,50$, and $60 \mathrm{~cm}$ are shown in Table 2 .

Apart from void ratio of surface soil, which is higher due to farming, void ratios increase with underground depth up to $60 \mathrm{~cm}$, but are almost not beyond 0.500 .

3.3. Dry Density of the Local Saline-Alkali Soil. Distribution of dry densities of the local saline-alkali soil is coupling with that of void ratios, as shown in Table 3.

Apart from dry density of surface soil, which is lower due to farming, the dry densities decrease with underground depth up to $60 \mathrm{~cm}$, but are all beyond $1.600 \mathrm{~g} / \mathrm{cm}^{3}$.

3.4. Mineral Composition of the Saline-Alkali Soil. Mineral composition of the local saline-alkali soil is studied by using TD-3500 X-ray diffractometer, as shown in Table 4 .

Because the average ratio of clay minerals of illite, kaolinite, and chlorite is only $12.24 \%$, the saline-alkali soil in the study area does not have typical clay properties; that is to say, clay minerals are not the main reason for poor water permeability of the saline-alkali soil.

3.5. Compact Structure of the Saline-Alkali Soil. After preparing soil samples by the liquid nitrogen vacuum freezedrying method and processing them by IB- 5 ion sputtering instrument, scanning pictures of the local saline-alkali soil at depths of $0,10,20,30,40,50$, and $60 \mathrm{~cm}$ have been received by FEI Quanta250 high- and low-vacuum scanning electron microscope in the US. Scanning pictures enlarged 1000 times are shown in Figure 2.

In microscopic space, the local saline-alkali soil may be with compact structure and extremely weak permeability, among which developing degree of the surface soil is only lower. Water infiltration passageway will mainly depend on slightly developing fracture in the local saline-alkali soil, especially the surface soil; hence, there should not be typical interflow in it.

\section{Surface Runoff Mechanism and Water-Salt Migration Rule of the Local Saline-Alkali Soil}

In research area of the saline-alkali soil in the Yellow River Delta, the weather from July to December 2018 was mainly cloudy, so little precipitation would return to the atmosphere due to ground evaporation. Surface soil is easy to form saturated layer because of its relatively developed fractures, looser structures, developed pores, and well permeability. The other parts of the soil will not present typical interflow because of compact structures, limited fractures, and weak permeability. In the studying period, each saturated state of surface soil was followed with a heavy rainfall which increased the surface runoff coefficient. Therefore, the 
TABLE 1: Volume ratios of pores of the local saline-alkali soil (\%).

\begin{tabular}{lcccccccc}
\hline \multirow{2}{*}{ Pore diameter $(\mu \mathrm{m})$} & \multicolumn{9}{c}{ Depth of soil specimen $(\mathrm{cm})$} & \multicolumn{3}{c}{ Average volume ratio $(\%)$} \\
& 0 & 10 & 20 & 30 & 40 & 50 & 60 & \\
\hline$d \geq 20$ & 9.67 & 8.82 & 4.61 & 3.42 & 6.38 & 3.58 & 2.39 & 13.75 \\
$10 \leq d<20$ & 10.30 & 1.56 & 1.32 & 2.15 & 2.16 & 0.76 & 0.49 & \\
$2 \leq d<10$ & 13.03 & 1.35 & 0.37 & 1.37 & 4.39 & 9.28 & 8.88 & \\
$0.1 \leq d<2$ & 46.02 & 34.02 & 44.26 & 39.93 & 47.81 & 46.77 & 51.41 & 86.25 \\
$d<0.1$ & 20.98 & 54.25 & 49.44 & 53.13 & 39.26 & 39.61 & 36.83 & \\
\hline
\end{tabular}

TABLe 2: Void ratios of the local saline-alkali soil.

\begin{tabular}{lc}
\hline Depth $(\mathrm{cm})$ & Void ratio \\
\hline 0 & 0.536 \\
10 & 0.243 \\
20 & 0.263 \\
30 & 0.257 \\
40 & 0.331 \\
50 & 0.353 \\
60 & 0.511 \\
\hline
\end{tabular}

TABle 3: Dry densities of the local saline-alkali soil.

\begin{tabular}{lc}
\hline Depth $(\mathrm{cm})$ & Dry density $\left(\mathrm{g} / \mathrm{cm}^{-3}\right)$ \\
\hline 0 & 1.671 \\
10 & 2.025 \\
20 & 1.955 \\
30 & 1.998 \\
40 & 1.849 \\
50 & 1.795 \\
60 & 1.651 \\
\hline
\end{tabular}

surface runoff mode is slope flow above saturated layer and without miscible flow.

If the permeability of the middle and lower saline-alkali soil is very weak, the water could not carry salt to deeper area. However, the surface soil will immediately produce surface runoff if it meets a heavy rainfall when it is in saturated state, which would migrate together with salt.

\section{Salt-Discharging Engineering Model for the Local Saline-Alkali Soil}

The surface soil will produce surface runoff after being saturated and the other parts may be with compact structures, poor permeability, and lack of interflow, so the saltdischarging engineering model considering mainly surface runoff, auxiliary infiltration, and no interflow is constructed for the local saline-alkali soil, in which the slope of open pitch is designed as 3 5\%o, as shown in Figure 3. Salt in the surface soil will be carried to the open pitch by surface runoff, which would significantly reduce its salt content.

\section{Distribution of Salt Contents of the Local Saline-Alkali Soil}

6.1. Relationship between Salt Content and Conductivity of the Local Saline-Alkali Soil. Sampling 84 specimens of the saline-alkali soil with deep positions ranging from 0 to
$1000 \mathrm{~mm}$ was performed 3 times $(2018.08 .13$; 2018.11.07 11.08; 2018.11.30 12.01); salt contents of 42 samples of these are determined using the drying method; and relationship between salt content and conductivity is shown in Figure 4.

Equation (1) was established by fitting relationship between salt content and conductivity of the local saline-alkali soil, based on which salt contents of the other soil samples will be determined only by testing their conductivities:

$$
y=-0.00186+2.74139 x \approx 2.74 x \text {. }
$$

In the formula, correlation coefficient is $0.9967, y$ is the salt content (\%), and $x$ is the conductivity $(\mathrm{mS} / \mathrm{mm})$.

6.2. Relationship between Salt Content and Depth of the Local Saline-Alkali Soil. Based on the experiment, the salt content of samples was measured, and the relationship between the salt content and the depth of saline-alkali soil was established, as shown in Figure 5.

Salt contents of the local saline-alkali soil decrease with increasing depths and will tend towards steady level when its depth reaches $60 \mathrm{~cm}$; therefore, the depth of salt-discharging engineering such as open pitch should be deeper than $60 \mathrm{~cm}$.

\section{Engineering Application of the Salt- Discharging Model}

The designing depth of open pitch is $60 \mathrm{~cm}$ which is used to verify the applied effectiveness of the salt-discharging engineering model, as shown in Figure 6.

7.1. Lower and Steady Salt Contents in the Middle and Lower Area of the Saline-Alkali Soil. Salt contents of the middle and lower area of the saline-alkali soil were lower and steady in the studying period (Figure 5), which states that rainfall cannot produce typical infiltration and interflow, so there is no salt-discharging effect on the soil. Meanwhile, compact structure and poor permeability of the middle and lower area of the saline-alkali soil have been verified, and the saltdischarging engineering model having mechanisms of auxiliary infiltration and no interflow is suitable.

7.2. Significantly Decreased Salt Contents in the Surface Soil. Corresponding with distribution of daily rainfalls from national rainfall recording stations (2018, Guangrao County, Dongying City, Shandong Province, China), 3 times of sampling dates and 2 times of saturated soil dates are marked, as shown in Figure 7. 
TABLe 4: Proportions of minerals of the local saline-alkali soil (\%).

\begin{tabular}{|c|c|c|c|c|c|c|c|c|c|}
\hline \multirow{2}{*}{ Mineral } & \multicolumn{7}{|c|}{ Depth of soil specimen $(\mathrm{cm})$} & \multirow{2}{*}{\multicolumn{2}{|c|}{$\begin{array}{c}\text { Average proportion } \\
(\%)\end{array}$}} \\
\hline & 0 & 10 & 20 & 30 & 40 & 50 & 60 & & \\
\hline Quartz & 53.6 & 55.1 & 43.4 & 44.2 & 51.9 & 60.9 & 50.8 & 51.43 & \\
\hline Calcite & 14.3 & 17.0 & 11.6 & 19.1 & 15.8 & 13.6 & 13.9 & 15.04 & \\
\hline Orthoclase & 0 & 4.3 & 2.6 & 7.1 & 3.6 & 5.3 & 3.1 & 3.71 & 87.76 \\
\hline Kozulite & 0 & 1.3 & 0 & 0 & 0 & 0 & 2.1 & 0.48 & \\
\hline Albite & 19.1 & 7.7 & 32.6 & 19.4 & 15.7 & 11.7 & 10.7 & 16.69 & \\
\hline Hematite & 0.8 & 0.9 & 0 & 0 & 0 & 0 & 1.2 & 0.41 & \\
\hline Illite & 7.4 & 9.7 & 3.8 & 5.7 & 8.3 & 6.2 & 9.1 & 7.17 & 12.24 \\
\hline Kaolinite & 3.3 & 1.5 & 3.1 & 1.6 & 2.5 & 0.6 & 7.1 & 2.81 & \\
\hline Chlorite & 1.5 & 2.5 & 2.9 & 2.9 & 2.1 & 1.8 & 2.1 & 2.26 & \\
\hline
\end{tabular}

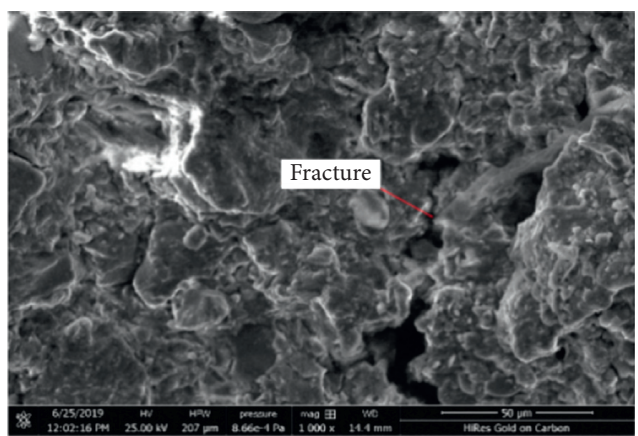

(a)

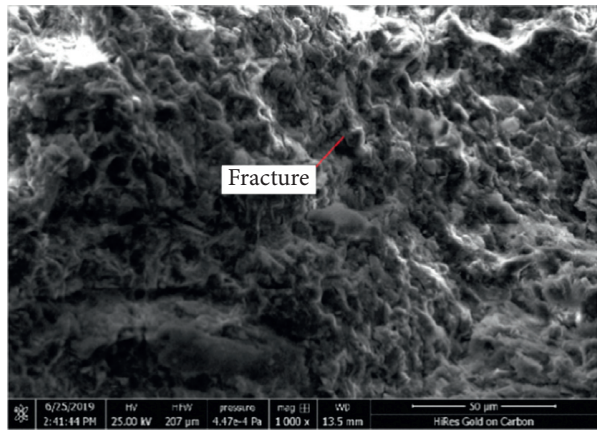

(c)

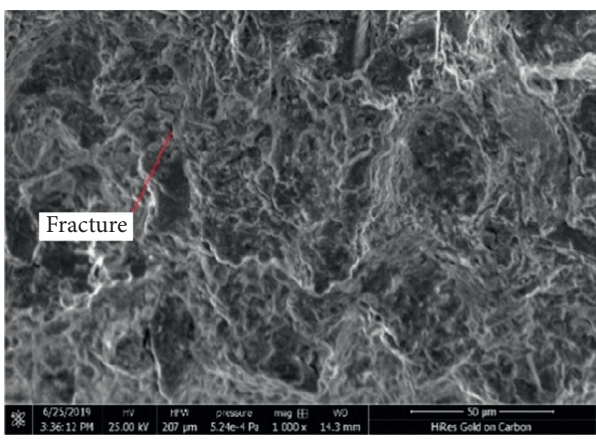

(e)

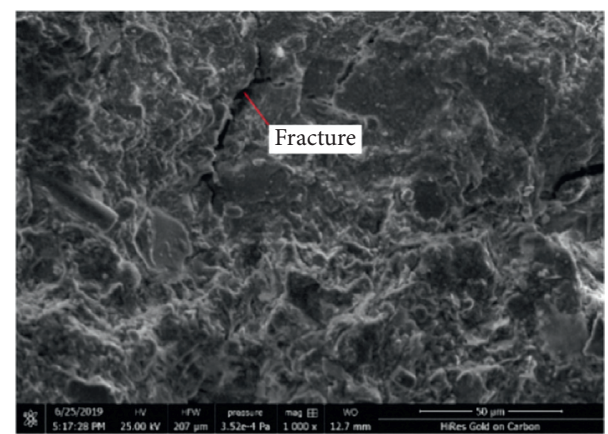

(b)

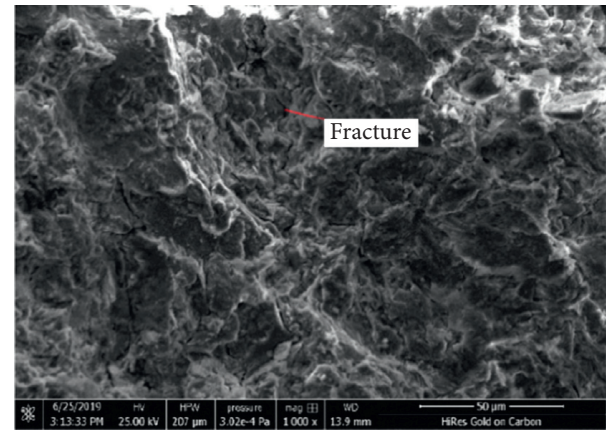

(d)

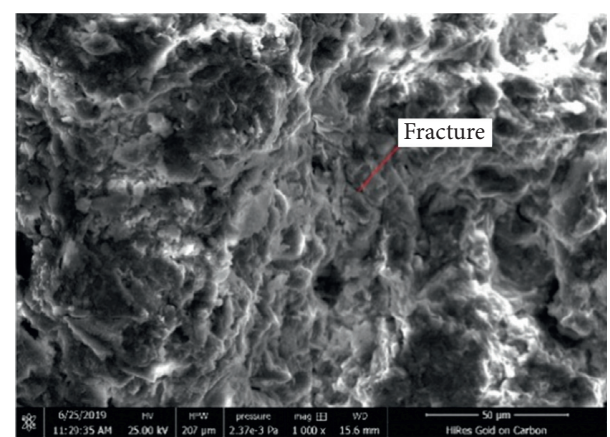

(f)

Figure 2: Continued. 


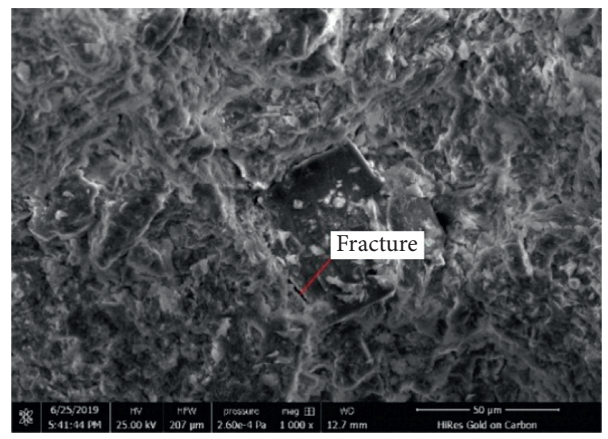

(g)

FIGURE 2: Scanning pictures of the local saline-alkali soil (enlarge 1000 times). (a) Surface soil. (b) Soil at depth $10 \mathrm{~cm}$ underground. (c) Soil at depth $20 \mathrm{~cm}$ underground. (d) Soil at depth $30 \mathrm{~cm}$ underground. (e) Soil at depth $40 \mathrm{~cm}$ underground. (f) Soil at depth $50 \mathrm{~cm}$ underground. (g) Soil at depth $60 \mathrm{~cm}$ underground.

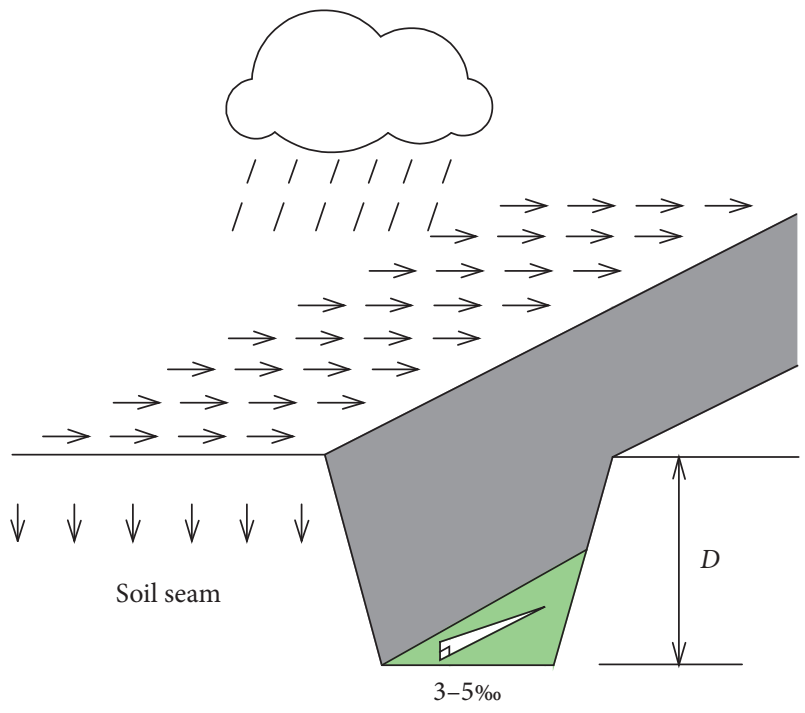

FIGURE 3: Sketch of the salt-discharging engineering model.

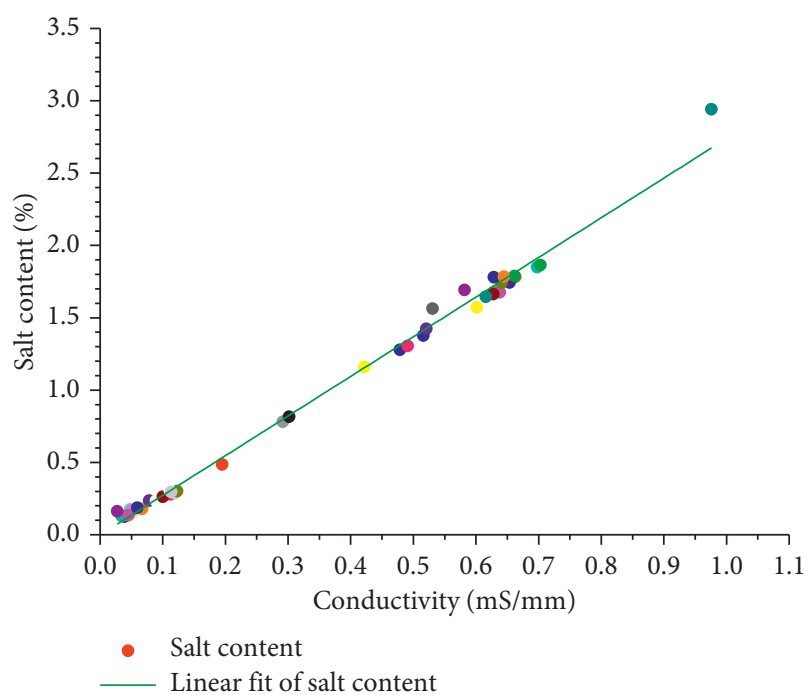

FIGURE 4: Relationship between salt content and conductivity of the local saline-alkali soil.

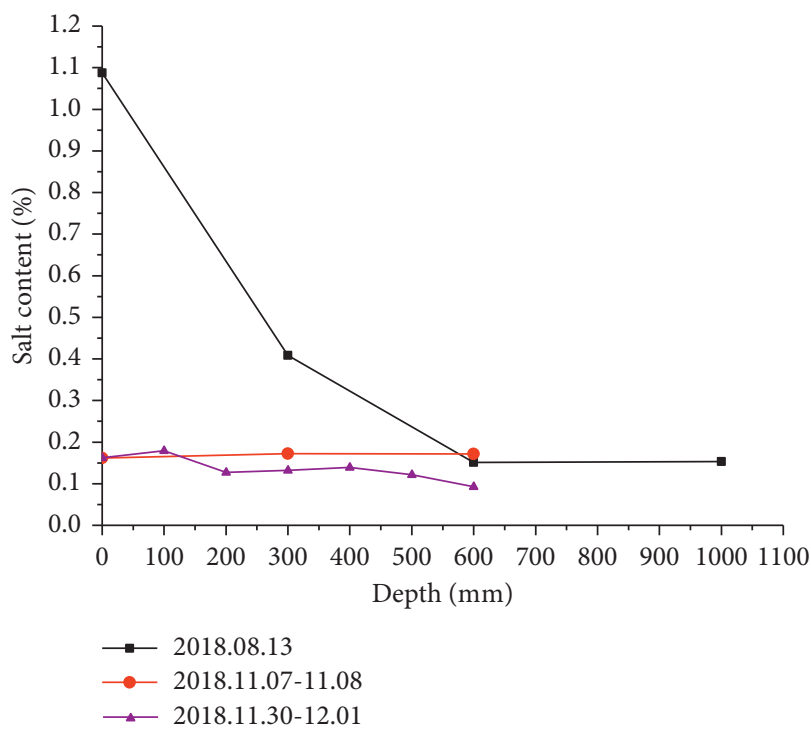

FIgURE 5: Relationship between salt content and depth of the saline-alkali soil.

Analyzing daily rainfalls we have found that the local saline-alkali soil has presented 2 times (before August 13 and before August 30) of surface saturated states from July to December, in 2018, each time with a heavy rainfall, which are the adequate and necessary conditions to produce surface runoff. Salt contents of samples of the surface saline-alkali soil decrease significantly (Figure 5) after 2 times of surface runoff actions on saturated soil layer. Obvious salt-discharging effectiveness verifies that surface saline-alkali soil has looser structure, well permeability, and developed pores, and the salt-discharging engineering model mainly considering surface runoff is correctable.

7.3. Auxiliary Evidences of the Salt-Discharging Model Dominated by the Surface Runoff. In Figure 7, the sampling period between the second date and the third date is 23 days (2018.11.08-2018.11.30), and rainfall is only $23 \mathrm{~mm}$ and not concentrated. Obviously, there is no surface runoff in the 


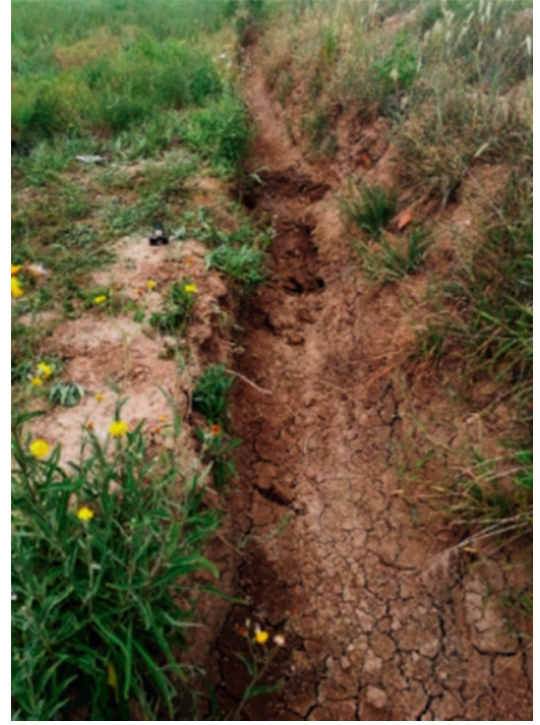

(a)

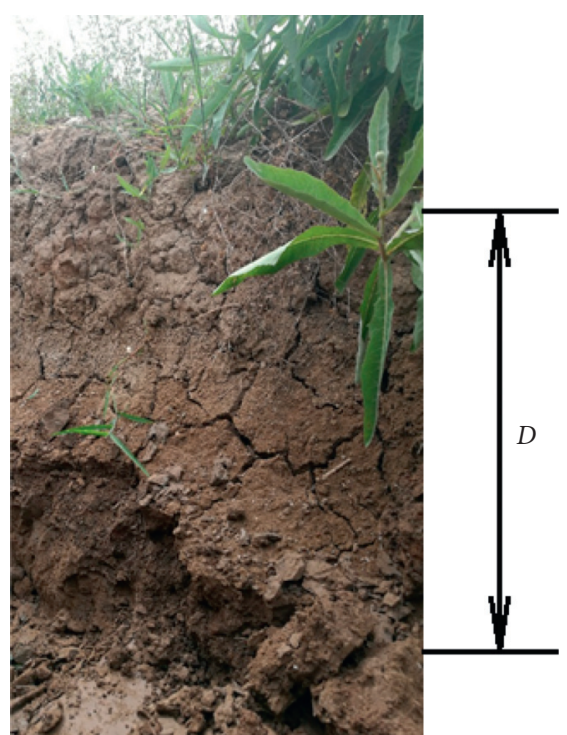

(b)

FIgURE 6: Open pitch used in salt-discharging field.

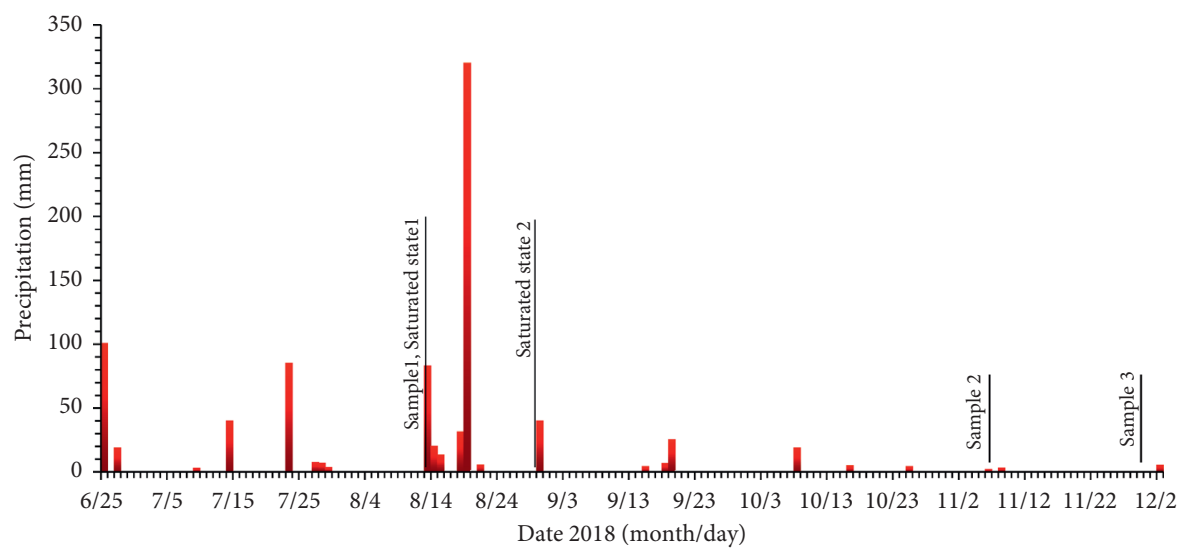

FIGURE 7: Daily rainfalls in the local saline-alkali soil (2018).

period, and the difference of salt contents between the two soil samples is very small (Figure 5), which indirectly proved that surface runoff is the determined reason for salt-discharging methods, and the salt-discharging engineering model would be suitable to manage the local saline-alkali soil.

\section{Main Conclusions}

(1) Structural characteristics of the local saline-alkali soil in the Yellow River Delta region are compact structures and slightly developed fractures, which mainly consisted of micropores and ultramicropores, lower void ratios, higher dry densities, lack of clay minerals, and micropermeable and extremely micropermeable water.

(2) The surface runoff mode of the local saline-alkali soil is slope flow above saturated layer and without miscible flow; therefore, salt in the surface soil would be carried to open pitch by surface runoff and that in the other parts of the soil must not migrate.

(3) The salt-discharging engineering model considering mainly surface runoff, auxiliary infiltration, and no interflow was established based on structural characteristics, mechanisms of surface runoff, and watersalt migration.

(4) Salt contents of experimental samples in the local saline-alkali soil region decrease with increasing depths, so the depth of the salt-discharging engineering of open pitch should not be beyond $60 \mathrm{~cm}$.

(5) The relationship between rainfall and salt content shows that salt contents in the middle and lower soil are lower and steady. In the surface of the salinealkali soil, the salt contents decrease significantly after two times of surface runoff, and the salt contents did not change without surface runoff, and it is directly or indirectly proved that the salt-discharging 
engineering model is suitable for managing the local saline-alkali soil.

\section{Data Availability}

The data used to support the findings of this study are available from the corresponding author upon request.

\section{Conflicts of Interest}

The authors declare that they have no conflicts of interest.

\section{Acknowledgments}

The financial supports for this research, from the Key Development Program for Research of Shandong Province (Grant no. 2018GNC110023) and the National Natural Science Foundation of China (Grant no. 51574156), are gratefully acknowledged.

\section{References}

[1] C. Temiz and G. Cayci, "The effects of gypsum and mulch applications on reclamation parameters and physical properties of an alkali soil," Environmental Monitoring and Assessment, vol. 190, no. 6, pp. 347-358, 2018.

[2] M. F. Qayyum, M. Z. Rehman, S. Ali et al., "Residual effects of monoammonium phosphate, gypsum and elemental sulfur on cadmium phytoavailability and translocation from soil to wheat in an effluent irrigated field," Chemosphere, vol. 174, pp. 515-523, 2017.

[3] T. Heng, R. Liao, Z. Wang, W. Wu, W. Wu, and J. Zhang, "Effects of combined drip irrigation and sub-surface pipe drainage on water and salt transport of saline-alkali soil in Xinjiang, China," Journal of Arid Land, vol. 10, no. 6, pp. 932-945, 2018.

[4] J. K. Mitchell and K. Soga, Fundamentals of Soil Behavior, John Wiley and Sons, Hoboken, NJ, USA, 2005.

[5] F. Cotecchia and R. J. Chandler, "A general framework for the mechanical behaviour of clays," Géotechnique, vol. 50, no. 4, pp. 431-447, 2000.

[6] A. K. Jha and P. V. Sivapullaiah, "Volume change behavior of lime treated gypseous soil - influence of mineralogy and microstructure," Applied Clay Science, vol. 119, pp. 202-212, 2016.

[7] A. Ahmed, "Compressive strength and microstructure of soft clay soil stabilized with recycled bassanite," Applied Clay Science, vol. 104, pp. 27-35, 2015.

[8] X. W. Zhang and L. W. Kong, "Study of pore characteristics of offshore clay by SEM and MIP and NA methods," Rock and Soil Mechanics, vol. 34, no. S2, pp. 134-142, 2013.

[9] J. Guo, J. S. Shi, H. Ye et al., "Remote sensing modelling of groundwater level distribution in the Yellow River Delta," Hydrogeology and Engineering Geology, vol. 36, no. 2, pp. 19-24, 2009.

[10] F. Zhang, W. J. Zhang, Y. Y. Ding et al., "XRD diffraction characteristics and microscopic morphology of carbonates in saline-alkali soil from the shore of the Aibi lake," Spectroscopy and Spectral Analysis, vol. 37, no. 12, pp. 3893-3899, 2017.

[11] B. H. Li, G. X. Zhao, C. Dong et al., "Dynamic and driving force analysis of salinized land in the Yellow River Delta based on RS and GIS," Journal of Natural Resources, vol. 26, no. 2, pp. 310-318, 2011.
[12] Y. B. Jiao, X. Y. Tian, and B. Q. Hu, "Dynamic change and remote sensing information extraction of saline land in the yellow river delta-A case study in Shandong Kenli County," Popular Science and Technology, vol. 18, no. 208, pp. 31-34, 2016.

[13] B. H. Li, G. X. Zhao, Y. W. Qin et al., "A study of remote sensing detection of salt-affected coastal land degradation in the Yellow River Delta," Acta Agriculturae Universitatis Jiangxiensis, vol. 31, no. 6, pp. 1166-1171, 2009.

[14] Z. R. Wang, G. X. Zhao, M. X. Gao et al., "Characteristics of soil water and salt spatial variations in the spring season in typical Yellow River Delta areas of Kenli County, China," Journal of Agricultural Resources and Enviornment, vol. 32, no. 2, pp. 154-161, 2015.

[15] Z. R. Wang, G. X. Zhao, M. X. Gao et al., "Spatial variation of soil water and salt and microscopic variation of soil salinity in summer in typical area of the Yellow River Delta in Kenli County," Acta Ecologica Sinica, vol. 36, no. 4, pp. 1040-1049, 2016.

[16] B. Guo, The Research on Saline-Alkali Soil Grading and Governance of the Yellow River Delta Based on the RS and GIS, Shandong Normal University, Jinan, China, 2015.

[17] T. F. Fu, Y. Zhang, J. W. Gao et al., "Study on spitio-temporal variability of salinity in the Yellow River delta," Periodical of Ocean University of China, vol. 47, no. 10, pp. 50-60, 2017.

[18] Q. Y. Zang, Nearshore Sediment in the Yellow River Delta, China Ocean Press, Beijing, China, 1996.

[19] Q. C. He, J. X. Xu, B. Zhang et al., Geological Environment and Sustainable Development of the Yellow River Delta, Geological Publishing House, Beijing, China, 2006.

[20] Y. M. Luo, Y. Li, H. B. Zhang et al., Soil and Environment of the Yellow River Delta, Science Press, Beijing, China, 2017.

[21] T. Bai and Q. Huang, Regulation and Control of Water and Sediment in the Desert Wide Valley of the Upper Reaches of the Yellow River, China Water \& Power Press, Beijing, China, 2017.

[22] J. H. Xu, Y. P. Lin, C. J. Wu et al., Study on the Definition of Concentrated Source Area of Coarse Sediment in the Middle Reaches of the Yellow River, Yellow River Conservancy Press, Zhengzhou, China, 2006.

[23] Z. L. Hui and W. K. Liu, "Study on the distribution characteristics of the Yellow River sediment and its reasonable control," Technology Innovation and Application, vol. 12, pp. 37-39, 2018.

[24] Ministry of Water Resources of the People's Republic of China, GB50487-2008 Code for Engineering Geological Investigation of Water Resources and hydropower, China Planning Press, Beijing, China, 2009.

[25] D. L. Shear, H. W. Olsen, and K. R. Nelson, Effects of Desiccation on the Hydraulic Conductivity versus Void Ratio Relationship for a Natural Clay, National Academy Press, Washington, DC, USA, 1993. 